\title{
Inhaled budesonide does not prevent acute mountain sickness after rapid ascent to $4559 \mathrm{~m}$
}

\author{
To the Editor:
}

Recent studies showed that inhaled budesonide $(200 \mu \mathrm{g}$ twice per day) reduced the incidence of acute mountain sickness (AMS) after passive ascent to 3700 and $3900 \mathrm{~m} \mathrm{[1,2].} \mathrm{These} \mathrm{findings} \mathrm{raised} \mathrm{the}$ possibility that mediators released from the hypoxic lung transmit signals to the brain which contribute to the cerebral processes leading to AMS [3]. Because neither of these studies reflect alpine-style climbing, the present study was performed to test whether inhalation of budesonide at two different doses (200 and $800 \mu \mathrm{g}$ twice per day) prior to active and rapid ascent $(<20 \mathrm{~h})$ to $4559 \mathrm{~m}$ prevents AMS in this high-risk setting.

The study was performed in accordance with the Declaration of Helsinki, and was approved by the Ethical Committee Salzburg, Austria, the Ethical Committee of the University of Torino, Italy, and the Austrian Competent Authority, Vienna. The trial was registered at ClinicalTrials.gov (NCT02811016) and conducted as a prospective, randomised, double-blind and placebo-controlled study, with group stratification according to gender, age and physical fitness.

After written informed consent was obtained, 50 healthy, non-acclimatised lowlanders were included in the study. Subjects were randomly assigned to receiving $200 \mu \mathrm{g}$ budesonide twice per day (B200, $\mathrm{n}=16$ ), $800 \mu \mathrm{g}$ budesonide twice per day $(\mathrm{B} 800, \mathrm{n}=17)$ or lactose-monohydrate (placebo, $\mathrm{n}=17$ ). Subjects were instructed in the correct use of the single-dosed capsules in the inhaler (Cyclohaler ${ }^{\oplus}$ PB Pharma, Meerbusch, Germany). Complete emptying of the capsules was visually verified. Inhalations were performed at 07:00 $\mathrm{h}$ and 19:00 h, starting 1 day prior to ascent and continued until the end of the study. At high altitude, all inhalations were performed under supervision to ensure correct inhalation technique.

Baseline measurements were performed at an altitude of $423 \mathrm{~m}$ (Salzburg, Austria). Two to four weeks later, subjects ascended from $1130 \mathrm{~m}$ (Alagna, Italy) to $4559 \mathrm{~m}$ within $\sim 20 \mathrm{~h}$. The ascent consisted of transport by cable car to $3275 \mathrm{~m}$, a 90-min climb to $3611 \mathrm{~m}$ (Capanna Gnifetti), where they spent the night, and a 4-5 h climb to $4559 \mathrm{~m}$ (Capanna Regina Margherita, Monte Rosa). Tests were performed 7 , 20,32 and $44 \mathrm{~h}$ after arrival at $4559 \mathrm{~m}$.

AMS was evaluated using the Lake Louise score (cumulative self-report plus clinical scores) and the AMS-C score of the abbreviated version of the Environmental Symptoms Questionnaire [4, 5]. Individuals were considered AMS-positive when they had a Lake Louise score $\geqslant 5$ in combination with an AMS-C score $\geqslant 0.70$ points [6].

Oxygen saturation $\left(\mathrm{SpO}_{2}\right)$ was measured by pulse oximetry (Covidien Nellcor, Mansfield, USA). Blood gas analysis was performed on capillary blood (Siemens, RapidPoint 500, Germany). Adrenocorticotropic hormone $(\mathrm{ACTH})$ and cortisol were measured in venous blood samples. Cortisol was also measured in 24 h-urine.

The primary end-point of the study was the occurrence of AMS. In previous studies, budesonide reduced AMS by between $60 \%$ and $75 \%[1,2]$. Sample-size estimation based on an effect size of 0.5 , an $\alpha$-error of 0.05 , and a power (1- $\beta$ error probability) of 0.80 yielded a total sample size of 44 for the three study groups. Differences in incidence of AMS were analysed by Chi-squared test. Differences in AMS severity were analysed by two-way-repeated-measures-ANOVA and pairwise multiple comparisons using the

@ERSpublications

Prophylactic inhalation of budesonide does not prevent acute mountain sickness after rapid ascent to high-altitude http://ow.ly/Bc9p30dOz46

Cite this article as: Berger MM, Macholz F, Sareban M, et al. Inhaled budesonide does not prevent acute mountain sickness after rapid ascent to 4559 m. Eur Respir J 2017; 50: 1700982 [https://doi.org/10.1183/ 13993003.00982-2017]. 

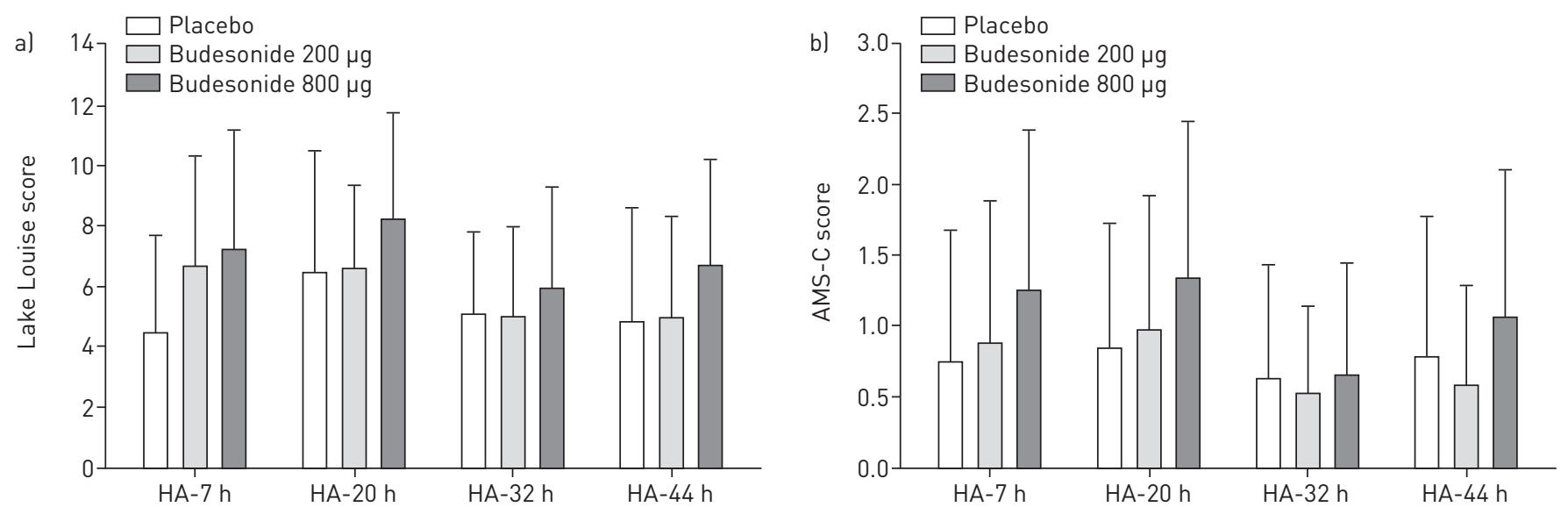

FIGURE 1 Severity of acute mountain sickness (AMS) as indicated by the Lake Louise score (a), and the AMS-C score of the Environmental Symptoms Questionnaire Cerebral scoring system (b). HA: high altitude (4559 m). Data are presented as mean \pm SD.

Student-Newman-Keuls test. Data are presented as mean \pm SD. A $p \leqslant 0.05$ (two-sided) was considered significant.

The baseline values were not different between study groups. Ascent to high altitude significantly increased AMS scores $(\mathrm{p}<0.001)$ without significant intergroup differences (figures $1 \mathrm{a}$ and $\mathrm{b}$ ). There was also no significant difference in the incidence of AMS (overall incidence: 53\%, 56\% and 76\% for the placebo, B200 and $\mathrm{B} 800$ groups, respectively, $\mathrm{p}=0.768$ ). Owing to severe AMS, one subject in the B800 and three subjects in the placebo group were treated with oxygen, acetazolamide, and oral dexamethasone after 9, 10, 21 or $35 \mathrm{~h}$ at $4559 \mathrm{~m}$. Data collection was terminated thereafter. Results from the blood gas analyses and hormone measurements are shown in table 1.

This study shows that inhalation of budesonide at 200 and $800 \mu \mathrm{g}$ twice per day reduced neither the incidence nor the severity of AMS in this high-risk setting of fast ascent to $4559 \mathrm{~m}$ within $\sim 20 \mathrm{~h}$, which is in contrast to the protective effect of budesonide inhalation $(200 \mu \mathrm{g}$ twice per day) during passive ascent to $3700 \mathrm{~m} \mathrm{[2]} \mathrm{and} 3900 \mathrm{~m} \mathrm{[1].}$

The incidence of AMS in the placebo group of our study is in accordance with previous studies [7-9]. The criterion we used for diagnosing AMS (Lake Louise score $\geqslant 5$ points in combination with an AMS-C score $\geqslant 0.70$ points) has a sensitivity and specificity of $\sim 80-90 \%$ for identifying those who feel sick or those who have to reduce activity at an altitude of $4559 \mathrm{~m}$ [10]. Even analysing potential budesonide effects based on a Lake Louise score $\geqslant 3$, which the two previous studies $[1,2]$ had used to detect mild AMS, shows that budesonide inhalation was ineffective in preventing AMS at $4559 \mathrm{~m}$. Applying this criterion to our study, the incidence of AMS in subjects with headache was $88 \%, 81 \%$ and $100 \%$ for the placebo, B200 and B800 groups, respectively.

Although in the two previous studies, the medication protocols were slightly different from ours, this does not explain the different outcomes. Indeed, in all studies, inhalation was started before ascent. Budesonide was administered at a dosage of $200 \mu \mathrm{g}$ twice per day for 3 [2] and 4 [1] days in the previous studies, while in our study budesonide was administered at 200 and $800 \mu \mathrm{g}$ twice per day for 4 days. Therefore, it is unlikely that in the present study, the dose and duration of medication were insufficient to reproduce the protective effect of budesonide from AMS. It is noteworthy, however, that in the two previous studies, measurements were performed 2 days after the last inhalation, while in our study inhalation was continued until all measurements were completed.

The results for $\mathrm{SpO}_{2}$, capillary $\mathrm{PO}_{2}$ and $\mathrm{PCO}_{2}$ (table 1) demonstrate that budesonide, independent of dosing, had no significant effects on gas exchange and ventilation compared to placebo. Subjects with AMS, compared to those without AMS, had on average slightly lower $\mathrm{SpO}_{2}$ and capillary $\mathrm{PO}_{2}$ values in the placebo and B200 but not in the B800 group (data not shown). These findings are in agreement with many previous studies reporting lower oxygenation in subjects with AMS [11-14]. In summary, our data indicate that inhalation of budesonide does not have a significant effect on pulmonary gas exchange.

Budesonide was given at $200 \mu \mathrm{g}$ twice per day in order to match the dose of the two previous studies [1,2]; the $800 \mu \mathrm{g}$ twice per day dose was chosen to achieve maximum efficacy. Plasma levels of ACTH and cortisol as well as the urinary excretion of cortisol over $24 \mathrm{~h}$ were not different between study groups (table 1) 
TABLE 1 Blood gas analysis and hormone levels at low and high altitude

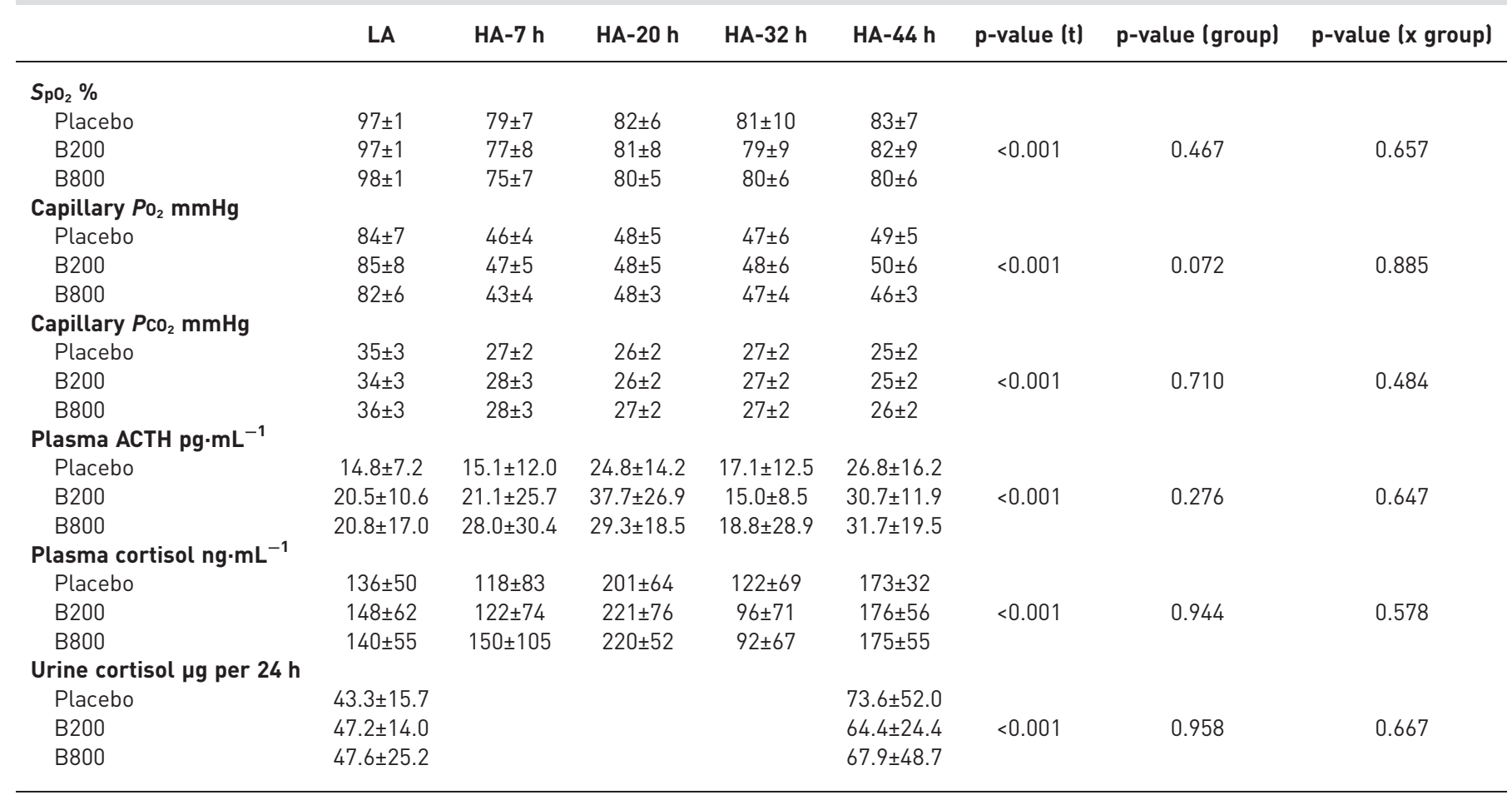

Data are presented as mean \pm SD from all individuals in each treatment group, with and without acute mountain sickness. $p$-value $(t)$ refers to $p$-value for differences over time; $p$-value (group) refers to $p$-value for differences between groups; and $p$-value ( $x$ group) refers to $p$-value for degree of interaction between factor $\mathrm{A}$ (time) and $\mathrm{B}$ (group). Oxygen saturation $\left(\mathrm{S}_{\mathrm{pO}_{2}}\right)$, as well as capillary oxygen tension $\left(\mathrm{PO}_{2}\right)$ and carbon dioxide tension $\left(\mathrm{PCO}_{2}\right)$, were decreased at high altitude $(\mathrm{p}<0.001)$ without a significant difference between the groups. Concentrations of cortisol and adrenocorticotropic hormone (ACTH) in plasma, as well as of free cortisol in 24-h urine samples, were increased at $4559 \mathrm{~m}$ but not significantly different between the groups. LA: low altitude (423 m, Salzburg. Austria); HA: high altitude (4559 m); B200 and B800: budesonide inhalation at $200 \mu \mathrm{g}$ and $800 \mu \mathrm{g}$ twice per day.

and demonstrate that even the higher dose of $2 \times 800 \mu \mathrm{g}$ budesonide per day did not supress the hypothalamic-pituitary-adrenal axis and thus had no systemic effects [15].

In conclusion, this study shows that inhalation of budesonide has no beneficial effect on the incidence and severity of AMS after active, rapid ascent to $4559 \mathrm{~m}$. Therefore, prophylactic inhalation of budesonide cannot be recommended for the prevention of AMS in a high-risk setting of alpine climbing to high altitudes. Moreover, our study does not support the hypothesis that pulmonary signalling, which might be locally suppressed by inhaled budesonide, contributes to the pathophysiology of AMS.

Marc Moritz Berger ${ }^{1,2}$, Franziska Macholz ${ }^{1}$, Mahdi Sareban ${ }^{3}$, Peter Schmidt ${ }^{1}$, Sebastian Fried ${ }^{4}$, Daniel Dankl ${ }^{1}$, Josef Niebauer $^{3}$, Peter Bärtsch ${ }^{4}$ and Heimo Mairbäurl ${ }^{4,5}$

${ }^{1}$ Dept of Anesthesiology, Perioperative and General Critical Care Medicine, Salzburg General Hospital, Paracelsus Medical University, Salzburg, Austria. ${ }^{2}$ Dept of Anesthesiology, University Hospital Heidelberg, Heidelberg, Germany.

${ }^{3}$ University Institute of Sports Medicine, Prevention and Rehabilitation, Paracelsus Medical University, Salzburg, Austria; Research Institute of Molecular Sports Medicine and Rehabilitation, Paracelsus Medical University, Salzburg, Austria.

${ }^{4}$ Dept of Internal Medicine VII, Division of Sports Medicine, University Hospital Heidelberg, Heidelberg, Germany.

${ }^{5}$ Translational Lung Research Center (TLRC), German Center for Lung Research (DZL), Heidelberg, Germany.

Correspondence: Marc Moritz Berger, Dept of Anesthesiology, Perioperative and General Critical Care Medicine, University Hospital Salzburg, Paracelsus Medical University, Müllner Hauptstr. 48, 5020 Salzburg, Austria. E-mail: ma.berger@salk.at

Received: March 272017 | Accepted after revision: June 082017

This trial was registered at ClinicalTrials.gov (NCT02811016).

Conflict of interest: None declared.

References

1 Zheng CR, Chen GZ, Yu J, et al. Inhaled budesonide and oral dexamethasone prevent acute mountain sickness. Am J Med 2014; 127: 1001-1009. 
2 Chen GZ, Zheng CR, Qin J, et al. Inhaled budesonide prevents acute mountain sickness in young Chinese men. J Emerg Med 2015; 48: 197-206.

3 Swenson ER. The lungs in acute mountain sickness: victim, perpetrator, or both? Am J Med 2014; 127: 899-900.

4 Roach RC, Bartsch P, Hackett PH, et al. The Lake Louise AMS Scoring Consensus Committee. The Lake Louise acute mountain sickness scoring system. In: Sutton JR, Houtson CS, Coates G, eds. Hypoxia and Molecular Medicine. Burlington, VT, Queen City Printers, 1993; pp. 272-274.

5 Beidleman BA, Muza SR, Fulco CS, et al. Validation of a shortened electronic version of the environmental symptoms questionnaire. High Alt Med Biol 2007; 8: 192-199.

6 Bailey DM, Dehnert C, Luks AM, et al. High-altitude pulmonary hypertension is associated with a free radical-mediated reduction in pulmonary nitric oxide bioavailability. J Physiol 2010; 588: 4837-4847.

7 Maggiorini M, Buhler B, Walter M, et al. Prevalence of acute mountain sickness in the Swiss Alps. BMJ 1990; 301: 853-855.

8 Bartsch P, Maggiorini M, Schobersberger W, et al. Enhanced exercise-induced rise of aldosterone and vasopressin preceding mountain sickness. J Appl Physiol 1991; 71: 136-143.

9 Goerre S, Wenk M, Bartsch P, et al. Endothelin-1 in pulmonary hypertension associated with high-altitude exposure. Circulation 1995; 91: 359-364.

10 Bartsch P, Bailey DM, Berger MM, et al. Acute mountain sickness: controversies and advances. High Alt Med Biol 2004; 5: 110-124.

11 Nespoulet H, Wuyam B, Tamisier R, et al. Altitude illness is related to low hypoxic chemoresponse and low oxygenation during sleep. Eur Respir J 2012; 40: 673-680.

12 Sutton JR, Bryan AC, Gray GW, et al. Pulmonary gas exchange in acute mountain sickness. Aviat Space Environ Med 1976; 47: 1032-1037.

13 Bartsch P, Swenson ER, Paul A, et al. Hypoxic ventilatory response, ventilation, gas exchange, and fluid balance in acute mountain sickness. High Alt Med Biol 2002; 3: 361-376.

14 Agostoni P, Swenson ER, Fumagalli R, et al. Acute high-altitude exposure reduces lung diffusion: data from the HIGHCARE Alps project. Respir Physiol Neurobiol 2013; 188: 223-228.

15 Lipworth BJ. Adrenal suppression with inhaled corticosteroids. Ann Allergy Asthma Immunol 2001; 87: 359-361. 